doi: $10.1590 /$ S0103-51502013000300001 ISSN 0103-5150

Fisioter. Mov., Curitiba, v. 26, n. 4, p. 711-712, set./dez. 2013

Licenciado sob uma Licença Creative Commons

\title{
Editorial
}

\section{Interdisciplinaridade: desafios para pesquisa e publicação}

Interdisciplinaridade é uma condição sine qua non para o desenvolvimento da ciência, da tecnologia e da inovação. Ela engloba problemas e necessidades reais, objetivando soluções integradoras, é fundamental na geração de conhecimento e não ocorre simplesmente pela junção de saberes de diferentes áreas, mas pela integração e compartilhamento de conhecimentos, habilidades e métodos que operacionalizem a criação de novos conceitos e técnicas advindos dessa junção. A pesquisa interdisciplinar, pela sua própria natureza, resulta em novas abordagens teórico-metodológicas e contribui com a formulação de novos paradigmas.

Nos últimos anos, a necessidade do desenvolvimento de pesquisas interdisciplinares tem sido discutida e apresentada, incluindo linhas específicas de incentivo dos órgãos de fomento, do governo e da indústria. Mas ainda existem algumas dificuldades, principalmente por estarmos acostumados a inserir, definir ou classificar os profissionais e as pesquisas em "compartimentos". Dominamos inúmeras possibilidades de separação em compartimentos, porém, não sabemos trabalhar para permitir uma visão integrada deles. Isso mostra que não estamos preparados para a interdisciplinaridade. Podemos citar como exemplo um projeto de registro eletrônico para prevenção da doença renal crônica, utilizando padrões para o desenvolvimento de sistemas de informação em saúde que não se ajustem às necessidades específicas da área de computação nem à de saúde pública. Nesse caso teríamos um projeto de duas áreas, envolvendo uma terceira, mas não a integrando.

Outra dificuldade encontrada é que ainda são poucos os periódicos que aceitam artigos não derivados de uma área específica ou que tenham autores de uma área de formação distinta da área principal da revista.

Esta revista é um veículo fundamental para divulgação de resultados de estudos interdisciplinares, devido à sua visão da importância da fisioterapia e à diversidade do seu corpo de revisores. Estudos que envolvem movimento humano, biomecânica e avaliação de tecnologias em saúde são intrinsecamente interdisciplinares e abordados de forma recorrente neste periódico. A parceria com o Programa de Pós-Graduação em Tecnologia em Saúde (PPGTS) da Pontifícia Universidade Católica do Paraná — que é interdisciplinar e neste ano completa dez anos ao longo dos quais foram desenvolvidos trabalhos que integram tecnologia e saúde - além de aumentar o corpo de revisores que conhecem e atuam de forma interdisciplinar, viabilizou a versão bilíngue, que a partir do próximo volume será ampliada para quase a totalidade dos artigos. Uma ótima leitura a todos e que cada vez mais possamos propor soluções para traduzirmos a interdisciplinaridade em pesquisa e publicação, pois a complexidade da ciência é de tal 
magnitude que nenhuma área isolada seria capaz de atender às crescentes demandas que se apresentam a cada dia para cidadãos, governos e instituições de pesquisa.

Os mais efusivos agradecimentos aos revisores que, ao longo deste ano, dedicaram seus melhores esforços para que os quatro fascículos fossem publicados.

Um Natal cheio de bênçãos e solidariedade a todos.

Profa. Dra. Claudia M. Cabral Moro Barra Mestrado em Tecnologia em Saúde PUCPR 